\title{
Retradução e o princípio da abundância
}

\author{
Simone Petry*
}

A pesquisa que venho realizando sobre o pensamento de Antoine Berman pode ser compreendida como um esforço de retradução da reflexão desse autor, realizada em textos cuja ordem de publicação não segue a cronologia em que os mesmos foram escritos, o que, como afirma Isabelle Berman (2008, p. 06), instaura um outro tempo nessa obra. Contudo, tanto para a releitura desses textos quanto para uma compreensão do conceito Bermaniano de retradução, que é o mote sobre o qual pretendo me debruçar aqui, não é só para esse tempo outro que devemos dar atenção especial, é preciso também ter em mente o movimento que sustenta todas as reflexões do autor e que se apresenta de modo mais marcante na composição do seu conceito de retradução. Movimento este que começou a germinar nas reflexões expostas pelo Idealismo alemão, depois foi reelaborado pelos românticos de Iena e segue até hoje contornando reflexões de pensadores de várias áreas das ciências humanas, como é o caso da reflexão de Antoine Berman, que faz, como todas as outras, uma releitura própria desse movimento, apropriando-se principalmente das leituras, bem como das traduções, que faz de textos de Friedrich Schlegel e de Novalis.

Marcio Suzuki (1998), em sua tese de doutorado, texto interessado centralmente no pensamento de Schlegel, nos faz notar que esse movimento surge da percepção filosófica (aqui Schlegel estaria lendo especialmente o idealista Schelling) de que era necessário "eliminar o dualismo de espírito e matéria" (p.109). Schlegel também não perde de vista o ideal da Doutrinada-ciência (de Fichte), para a qual somente a consciência que cada um tem de si e dos objetos poderia conferir realidade e validade objetiva àquilo que

\footnotetext{
* Universidade Estadual de Campinas/ FAPESP.
} 
a filosofia postula (p. 99-109), o que "significa também eliminar a separação entre necessidade e contingência - e isso não se fará insistindo na indubitável, porém estéril prioridade lógica do conceito, mas afirmando e explorando toda a densidade da 'vida'" (p. 109). Isso com vistas a promover uma unificação crítica de idealismo e realismo. A partir disso, é possível reconhecer que há no idealismo uma tendência inscrita na sua própria natureza. Eis a leitura do pensamento de Schlegel por Suzuki: “[...] o idealismo tem de 'sair de si [...]' e 'por isso sempre busca o realismo'. Mas essa 'saída de si', esse 'voltar à vida', representará também um verdadeiro 'retorno a si' da filosofia" (p. 111), num movimento interminável. A reflexão, que é o principal princípio dialético do idealismo, e também o que impulsiona esse movimento, "revela que o refletir sobre si é também sair de si: a 'reflexão necessária do eu sobre si mesmo é o fundamento de todo sair de si mesmo'" (p. 121). "Refletir sobre si, ensina a doutrina-da-ciência, implica sair de si, pôr um outro, um não-eu" (ibid.). A filosofia, diz ainda Suzuki, "deve deixar a imanência da razão, fazer-se de novo transcendente, sair de si, para voltar a ser 'filosofia da vida', isto é, tornar-se 'o produto da filosofia de um filósofo e de sua vida'” (p. 122, grifos do autor).

Mais adiante Suzuki nos apresenta, a partir de um dos fragmentos de Schlegel, um modo romântico desse movimento filosófico se manifestar: em forma de elipse. Assim, por ser elíptico, há nele dois centros: a lógica e a crítica (aqui já se pode entender a concepção romântica de que a própria filosofia é movimento, ou, é esse movimento). Na leitura de Suzuki:

[...] se um foco é a "lógica", o outro é a crítica, que se situa, portanto, num terreno "extralógico". Lógica (o interior, o "dentro") e crítica (o exterior, o "fora") constroem a totalidade da filosofia da vida, ocupando as mesmas posições que em outro fragmento estão reservadas ao idealismo e ao realismo (p. 131, grifo do autor).

Construiu-se, desse modo, o movimento que compõe a "filosofia cíclica" de Schlegel, como destaca Walter Benjamin no texto Conceito de crítica de arte no Romantismo alemão, de 1919, e também, conforme nos esclarece Márcio Seligmann (2011), nos oferece a "noção de 'desdobramento infinito' da reflexão: e da própria verdade [...] como Reflexão, movimento" (p. 11). 
Esse desdobramento infinito da reflexão, esse movimento crítico, que nada mais é do que a crítica da crítica, a metacrítica portanto, é o mesmo movimento que Berman designará, em L'épreuve de l'étranger (1984), como autoprocesso (referindo-se a Bildung), em que um mesmo se desdobra, sai de si, vai ao encontro do que lhe é diferente, do não-mesmo, até atingir sua plena dimensão. Segundo o autor francês, foi o refinado conceito de experiência, elaborado pelos românticos alemães, que forneceu a melhor interpretação desse processo, ou, autoprocesso (p. 74). Pois a experiência

est la seule notion pouvant embrasser toutes les autres. Elle est élargissement et infinitisation, passage du particulier à l'universel, épreuve de la scission, du fini, du conditionné. Elle est voyage [...], ou migration [...]. Son essence est de jeter le "même" dans une dimension qui va le transformer. Elle est le mouvement du "même" qui, changeant, se retrouve "autre". "Meurs et deviens", a dit Goethe.

Mais elle est aussi, en tant que voyage, expérience de l'altérité du monde : pour accéder à ce qui, sous le voile d'un devenir-autre, est en vérité un devenir-soi, le même doit faire l'expérience de ce qui n'est pas lui, ou du moins paraît tel. Pour l'Idéalisme, l'expérience aboutie est le devenir-soi de l'autre et devenir-autre du même (ibid., grifos do autor) ${ }^{1}$.

Esse autoprocesso, essa experiência, permeia em grande medida o pensamento de Berman. Está muito presente, por exemplo, na forma que ele dá aos seus textos. Vale lembrar que esse movimento, ou, essa reflexão metacrítica, como nos chama a atenção Medeiros (2014), é também impulsionado por um princípio dialético, cuja inspiração chega aos românticos através do processo dialógico de Platão, mas à diferença deste, em que o "debate das ideias ocorria com um interlocutor 'real'" (p. 53), no romantismo a reflexão se dá "por meio do diálogo consigo mesmo, no interior da

\footnotetext{
${ }^{1}$ [...] é a única noção que pode abraçar todas as outras. Ela é alargamento e infinitização, passagem do particular ao universal, prova de cisão, do finito, do condicionado. É viagem [...] ou migração [...]. Sua essência é jogar o "mesmo" em uma dimensão que vai transformá-lo. Ela é o movimento do "mesmo" que, mudando, encontra-se "outro". "Morra e transforme-se", disse Goethe.

Mas ela é também, enquanto viagem, experiência da alteridade do mundo: para ter acesso ao que, sob o véu de um tornar-se-outro, é na verdade um tornar-se-si, o mesmo deve fazer a experiência do que não é ele, ou pelo menos parece como tal. Para o Idealismo, a experiência concluída é o tornar-se-si do outro e o tornar-se-outro do mesmo (Berman, A. A prova do estrangeiro - Cultura e tradução na Alemanha romântica. Tradução Maria Emília Pereira Chanut. Bauru: Edusc, 2002. p. 81-82).
} 
obra [...]" (ibid.) - lembrando que, no idealismo, a filosofia da vida terá de privilegiar o "eu pessoal", a individualidade insubstituível, o gênio original de cada um. O princípio dialético é uma maneira de se dar destaque no texto à impossibilidade de realização da comunicação total e, por isso, uma possibilidade de se distanciar do assunto, de modo a poder voltar a ele, alçando-se acima da sua própria criação para tentar se expressar com maior lucidez (ibid., p. 54).

Os textos de Berman, desde os idos de 1967, quando ele ainda não tinha na tradução a sua questão de fundo, mas o primeiro romantismo alemão já estava no seu foco de estudos, já apresentavam esse viés dialógico na prática, na forma. Ele publicava cartas, as quais nunca esperavam por respostas do interlocutor; diálogos, sem definição dos interlocutores; e ensaios. Estes últimos são sua preferência após ser reconhecido como teórico da tradução. Nesses ensaios sempre encontramos muitas marcas da oralidade cuja função é a de explicitar o diálogo interno do texto. Essa estratégia pode ser considerada como parte do jogo irônico textual, muito semelhante às estratégias textuais românticas, o que possibilita que, textualmente, os interlocutores (eu e não-eu) se elevem em relação ao tema escolhido, de maneira que se possa observar uma mesma questão a partir de diversos ângulos, permitindo, com isso, que se revelem até mesmo as suas contradições. Mas a reflexão metacrítica, de inspiração romântica, não está presente apenas na forma como Berman realiza seus textos - forma que, como deve ter ficado claro, não se afasta do conteúdo. Assim, a reflexão metacrítica conduzirá todas as reflexões do autor e, muitas vezes, dará contornos a conceitos discutidos por ele, como é o caso do conceito de retradução.

A questão da retradução surge pela primeira vez no discurso de Berman na conclusão do texto L'épreuve de l'étranger, quando ele a destaca como um dos pontos mais importantes que envolvem a problemática da tradução do séc. $X X$, especialmente no que diz respeito à retradução de obras que, segundo ele, são fundamentais para a cultura ocidental. Nesse contexto, ele vai citar a Bíblia como carro chefe, e também textos da poesia e da filosofia gregas, da poesia latina, e os grandes textos importantes para o nascimento da literatura moderna (Dante, Shakespeare, Cervantes, etc.). Ele afirma, então, que toda tradução envelhece e, por isso, “c'est le destin 
de toutes les traductions des 'classiques' de la littérature universelle que d'être tôt ou tard retraduites" (p. 281)². Mas, e principalmente, ele também releva que a retradução no séc. $X X$ tem sentido mais específico:

\begin{abstract}
celui de nous rouvrir l'accès à des œuvres dont la puissance d'ébranlement et d'interpellation avait fini par être menacée à la fois par leur "gloire" (trop de clarté obscurcit, trop de rayonnement épuise) et par des traductions appartenant à une phase de la conscience occidentale qui ne correspond plus à la nôtre (ibid.) $)^{3}$.
\end{abstract}

O autor afirma, com isso, que esse desejo de que se reabra o acesso aos grandes textos da tradição histórica não cobre somente o campo da tradução, mas, também e ao mesmo tempo, o da hermenêutica e o da filosofia. Para sustentar essa ideia nos diz que basta considerar as grandes releituras da filosofia grega tentadas por Heidegger, "pour voir que ici [França] aussi, la tâche de la pensée est devenue une tâche de traduction" (ibid.) ${ }^{4}$. Portanto, podemos concluir que para Berman a tarefa da tradução é também a de ser reflexão.

Nesse momento, é importante relembrarmos que embora toda a discussão sobre tradução realizada por Berman possa ser adaptada a vários outros contextos, e essa característica é de enorme relevância para o pensamento desse autor, o discurso Bermaniano fala de um lugar bastante específico que precisamos sempre ter em conta. Berman fala do contexto francês, sua cultura e sua tradicional maneira do bem-traduzir, que, resumidamente, conforme salienta o próprio autor, prima pela clareza e adaptação cultural e linguística dos textos, seguindo um modelo que ganhou contornos entre os séc. XIV e XVI e a partir disso muito pouco se atualizou. Não gostaria aqui de mencionar que essa crítica se dirige especificamente à tradição tradutória das Belles infidèles, como muitas vezes se conclui apressadamente, porque a crítica de Berman não se dirige exatamente às normas

\footnotetext{
2 é o destino de todas as traduções dos "clássicos" da literatura universal serem, cedo ou tarde, retraduzidas (ibid., p. 315).

3 o de nos reabrir o acesso a obras cujo poder de comoção e interpelação acabara por ser ameaçado ao mesmo tempo por sua "glória" (clareza demais obscurece, brilho demais cansa) e por traduções pertencentes a uma fase da consciência ocidental que não corresponde mais à nossa (ibid., p. 315-16).

4 para ver que, aqui também [na França], a tarefa do pensamento tornou-se uma tarefa da tradução (ibid., p. 316).
} 
para a tradução estabelecidas por esse modelo específico (ele inclusive reconhece, por exemplo, a importância das traduções de D'Ablancourt para a história geral das traduções, e o considera como um dos grandes tradutores franceses); o que o autor questiona é a falta de atualização do pensamento sobre a tradução em pleno séc. $X X$, que no seu ponto de vista se reflete na prática tradutória atual, excluindo violentamente, principalmente do campo profissional, práticas divergentes (id., 2012, p. 05-15).

Com esse aparte em mente, quero retomar a discussão sobre a retradução. No texto La traduction et la lettre ou l'auberge du lointain (1999)5, Berman resgata, ou revisa, a questão da retradução na sua análise da tradução para o francês de Paraíso Perdido, de Milton, por Chateaubriand. Agora, ele não apenas destaca a importância da retradução e os motivos que a tornam fundamental para o fazer tradutório, para as obras envolvidas e, especialmente, para a cultura tradutora, como também começa a esboçar um espaço da retradução. Primeiramente, ele faz distinção entre "deux espaces (e deux temps) de traduction: celui des premières traductions, et celui des retraductions" (ibid., p. 104, grifos do autor) ${ }^{6}$. Segundo Berman, uma distinção entre essas duas categorias de tradução é fundamental para uma teoria se embasar e construir uma reflexão sobre a "temporalité $d u$ traduire" (ibid., grifo do autor $)^{7}$ - nesse momento, o autor não irá ainda estender seus argumentos sobre essa questão da temporalidade, mas acrescenta uma nota de rodapé em que chama a atenção para um dos momentos dessa reflexão, que seria a teoria do kairós, do momento favorável de uma tradução, que, segundo ele, teria sido apenas rascunhada em Goethe e Benjamin. Como primeira distinção de um espaço da retradução, Berman diz que ao retra-

\footnotetext{
${ }^{5}$ Berman, A. (2007): A tradução e a letra ou o albergue do longínquo. Tradução para o português brasileiro de Marie-Hélène Torres, Mauri Furlan e Andréia Guerini. Rio de Janeiro: 7letras. 143 p.

${ }^{6}$ dois espaços (e dois tempos) de tradução: das primeiras traduções e o das retraduções (ibid., p 96-97). Apenas para deixar registrado, Berman, nesse texto, utiliza o termo grafado com hífen, re-tradução, para dar destaque ao fato de se tratar do ato de repetição da tradução de um texto para o mesmo contexto linguístico, quantas vezes fosse necessário, a partir do original e de suas outras traduções já realizadas no mesmo idioma. Uma forma de marcar diferença em relação à outra acepção do termo utilizada na França, tradução indireta (conforme encontramos no dicionário francês Le Robert), que diria apenas da primeira tradução na língua de chegada. Mas, por ora, ainda não pretendo me estender nessa questão.

7 temporalidade do traduzir (ibid., p. 97, grifo do autor).
} 
duzir, o tradutor trabalha com dois ou mais textos, levando-se em conta o original, a sua primeira tradução e as suas possíveis retraduções realizadas.

$\mathrm{Na}$ primeira tradução, grosso modo, o tradutor se relaciona com apenas um texto, que é o texto a ser traduzido. Isso por si só já garante à retradução um espaço específico. Nesse espaço, ela vai ao encontro do texto original e de encontro às suas traduções existentes. Nesse espaço, também, segundo Berman, realizar-se-iam as obras-primas. Com isso, ele afirma que as primeiras traduções não são as maiores, e nem poderiam ser, devido às circunstâncias que as envolvem. Para ele, a "secundaridade" própria ao ato de traduzir se desdobra na retradução. Interessante notar que essa condição de segunda tradução da retradução, de acordo com o autor, é condição de todas as retraduções de uma mesma obra, ou seja, não existiriam terceiras traduções, apenas segundas - e essa afirmação é muito importante para percebermos que o autor tenta fugir de uma ideia comum de hierarquia. A definição de uma grande tradução seria, portanto, de que ela é "doublement seconde" (ibid., p. 105, grifo do autor) ${ }^{8}$, em relação ao original e em relação às outras traduções realizadas da mesma obra (ibid.). A importância desse desdobramento, que é a retradução, nos leva de novo ao movimento primeiro romântico da reflexão metacrítica e, desse modo, a grande tradução só pode se realizar se o tradutor aparecer enquanto agente nesse movimento.

Essas observações contradizem, segundo a minha leitura, a crítica segundo a qual o pesquisador Yves Gambier (2011) afirma que Berman, através do seu discurso sobre a retradução, estaria promovendo uma hierarquização, pois, na sua leitura do colega francês, cada retradução seria melhor que a sua antecessora até se chegar à perfeição. Isso seria, para Gambier, encontrar o sentido verdadeiro do texto original e, por isso, a realização de uma grande tradução, nessa leitura, seria um movimento cronológico e essencialista (p. 54-59). Primeiramente, ao relacionarmos o pensamento de Berman com a reflexão metacrítica dos primeiros românticos, ao menos a partir daquilo que esse autor recorta daquele pensamento, focado naquilo que lhe interessa defender, falar em essência imanente de algo esta-

\footnotetext{
8 duplamente segunda (ibid., grifo do autor).
} 
ria fora de cogitação. Quanto ao sentido do termo hierarquia, também precisaríamos pensar sobre a questão com maior cuidado, pois, na leitura que faço do texto de Berman, a grande tradução de um texto é, digamos, maior do que as suas segundas traduções, todas as retraduções dela existentes, mas não melhor do que elas, pois não há exatamente uma hierarquia, no sentido estrito do termo, porque a grande tradução necessita das retraduções anteriores para existir, as traduções anteriores são inerentes à grande tradução, e, além disso, vimos que a grande tradução, segundo Berman, é duplamente-segunda. Para ele, as retraduções são sinais do processo de amadurecimento das obras (Berman, 1999, p. 105).

No recém-lançado Jacques Amyot, traducteur français (2012), quando Berman diz que

\begin{abstract}
Privilégier les "grands traducteurs" ne signifie aucunement oublier ou mépriser les autres, car c'est grâce au labeur des "moins grands" que peuvent surgir les figures que nous évoquons [Berman havia destacado o nome de grandes tradutores como D'Ablancourt, Amyot, Chataubriand, A. Schlegel, Lutero, Tieck, Celan, entre outros]. La grande traduction est toujours préparée par d'autres traductions. Elle est toujours entourée ( $\mathrm{p}$. 147 , grifos do autor) $)^{9}$.
\end{abstract}

O que o autor nos diz é que, em alguma medida, todas as traduções realizadas de um mesmo texto constituíram num momento oportuno a sua grande tradução. Trata-se, reafirmo, de um movimento semelhante ao movimento romântico de reflexão metacrítica, sobre o qual falamos no início deste ensaio. Movimento semelhante, também, como bem lembra o próprio Berman, ao que constitui a famosa tríade Goetheana: tradução palavra por palavra (não literária), tradução adaptadora ou paródica, tradução interlinear elaborada.

Nesse rastro, o autor francês afirma que a tradução literal (nos termos Bermanianos: a tradução da letra - e letra, nesse contexto, diz da forma, da materialidade, da corporeidade do texto, do ritmo do discurso, das

\footnotetext{
9 Privilegiar os "grandes tradutores" não significa, de modo algum, esquecer ou desprezar os outros, pois graças ao trabalho dos "menores" que puderam surgir as figuras que nós evocamos. A grande tradução é sempre preparada pelas outras traduções. Ela é sempre circundada. (todas as traduções desse texto são de minha responsabilidade, para fins deste ensaio).
} 
cadeias do significante, etc.) é obrigatoriamente uma retradução e viceversa. Com isso, fica claro que uma grande tradução é uma tradução literal, que, por sua vez, será sempre retradução.

No texto "La retraduction comme espace de la traduction" (1990) ${ }^{10}$, Berman revisa novamente o conceito, e desta vez a retradução deixa de ter um espaço específico para ser o próprio espaço de realização. $\mathrm{O}$ autor diz na abertura desse ensaio: "Par 'espace', il faut entendre ici espace d'accomplissement. Dans ce domaine d'essentiel inaccomplissement qui caractérise la traduction, c'est seulement aux retraductions qu'il incombe $\mathrm{d}^{\prime}$ atteindre - de temps en temps - l'accompli (p. 01)"11. Ao retomarmos a ideia de Schlegel sobre o fato de a reflexão metacrítica se desdobrar infinitamente num movimento elíptico, entre os dois centros dessa elipse que marcam o espaço de idealização (espaço interno, o da lógica) e o espaço de realização (o externo, o da crítica), percebemos que a retradução, enquanto espaço de realização ou acabamento, é um movimento crítico. Essa será uma das maneiras para se entender o conceito de retradução nesse texto de Berman.

Na sequência, ainda em "La retraduction", o autor retoma os pontos da discussão elaborados nos seus textos anteriores, e alarga um pouco mais o conceito, começando por revisar a necessidade da retradução apenas como uma nova tradução de determinado texto. Retomando a questão do envelhecimento dos textos traduzidos, à diferença da obra original que no senso comum nunca envelhece, o autor pondera que, apesar de envelhecer, há o fato de que a primeira tradução não pode pretender ser $A$ tradução, com isso, a "possibilité et la nécessité de la retraduction sont inscrites dans la structure même de l'acte de traduire (ibid.) ${ }^{12 "}$. O autor reconhece, no entanto, que há exceções no princípio segundo o qual as traduções sempre envelhecem, pois algumas vezes uma tradução pode brilhar tanto ou mais que o original, e pode perdurar tanto quanto ele. Essas seriam, então, as grandes traduções, que, como já vimos, para Berman, diz respeito ao que

\footnotetext{
10 "A retradução como espaço da tradução".

11 Por "espaço" é preciso entender, aqui, espaço de realização. Nesse domínio de essencial irrealização que caracteriza a tradução, cabe somente às retraduções alcançar - de tempos em tempos - o realizado. (todas as traduções desse texto são de minha responsabilidade, para fins deste ensaio).

12 a possibilidade e a necessidade da retradução estão inscritas na própria estrutura do ato de traduzir.
} 
ele considera traduções literais, ou seja, realizadas normalmente a partir de um ciclo de retraduções. Assim, uma retradução não deveria ser considerada necessariamente apenas como a nova tradução de determinado texto, ela pode ser a grande tradução desse texto, pertencente a um cuidadoso processo de retraduções.

Nesse momento, uma nova questão é lançada pelo autor com o intuito de provocar, num movimento dialógico, o desvelamento das possíveis contradições do conceito que está sendo elaborado por ele: "Maintenant, pourquoi toute grande traduction est-elle nécessairement une retraduction ? Ou, à l'inverse, pourquoi toute première traduction n'est-elle jamais (ou presque) une grande traduction ?" (ibid., p. 04) ${ }^{13}$.

O que ficará claro no desenrolar do texto é que, na verdade, não existem primeiras traduções, porque não são publicadas absolutas primeiras versões. Explico: resgatemos a tríade Goetheana que Berman chama para a primeira parte da resposta desta problematização, e pensemos ao mesmo tempo no lugar de onde parte a crítica de Berman: um determinado contexto francês. Primeiramente, os três modos de se traduzir, segundo Goethe, representam também o ciclo de um processo tradutório, no melhor sentido da dialética do Idealismo, ou seja, como um movimento reflexivo. Nesses termos, o ciclo percorrido para a feitura de uma tradução seria: no ato tradutório primeiro, faz-se uma tradução palavra por palavra, depois parte-se para a adaptação (tradução etnocêntrica) ou para a tradução interlinear elaborada (no caso, a tradução literal nos termos de Berman). A questão da tradução palavra por palavra já está de certo modo ultrapassada. Ninguém, por exemplo, publicaria uma tradução nesses moldes atualmente, a não ser por um interesse estritamente específico. O que interessa, para Berman, é colocar em questão os dois últimos momentos do ato tradutório Goetheano. Assim, fica evidente que nenhuma primeira tradução pode ser uma grande tradução. E na medida em que os dois últimos modos pressupõem o primeiro, também é claro que uma tradução realizada só pode advir a partir do segundo modo, ou seja, já de uma "primeira" retradução. Assim nenhuma tradução apresentada, ou, publicada é primeira versão,

13 Agora, por que toda grande tradução é necessariamente uma retradução? Ou, ao contrário, por que toda primeira tradução nunca (ou quase nunca) é uma grande tradução? 
toda tradução é também retradução (ibid.). Em relação à dialética do Idealismo presente na reflexão de Goethe, Berman lembra os dizeres de Novalis, "tout début est maladroit" (ibid.) ${ }^{14}$. O autor conclui que no entender de Goethe "I faut tout le chemin de l'expérience pour parvenir à une traduction consciente d'elle-même. Toute première traduction est maladroite: se répète ici au niveu historique ce qui advient à tout traducteur : aucune traduction n'est jamais une 'première version'" (ibid.) ${ }^{15}$. Nesse sentido, toda tradução é uma retradução e, portanto, é desdobramento. Retradução também é movimento crítico que estabelece o espaço de amadurecimento desse processo pela experiência, pela circularidade infinita dessa reflexão, até chegar a um ponto em que a tradução, como toda ação humana, possa se realizar até se tornar algo grande, como uma grande tradução (ibid., p. 0405).

No auge da idealização desse conceito, Berman abordará essa problemática final de um outro modo, sem desconsiderar a sua leitura de Goethe, mas procurando se ater menos a uma percepção global do agir humano para se concentrar estritamente na estrutura particular da própria tradução. Ele procurará pensar a questão a partir de dois fatores que para ele são fundamentais: o kairós e a défaillance (ibid., p. 05). Ele diz:

\begin{abstract}
Si la défaillance, c'est-à-dire simultanément l'incapacité de traduire et la résistance au traduire, affecte tout acte de traduction, il y a néanmoins une temporalité de cet acte (temporalité aussi bien psychologique que culturelle et linguistique) qui fait que c'est en son début (dans le première traduction) que la défaillance est à son comble (ibid. $)^{16}$.
\end{abstract}

Para Berman, então, a retradução surgiria como uma tentativa de se reduzir essa espécie de entropia ${ }^{17}$ inicial (défaillance), na impossibilidade de

\footnotetext{
14 Todo início é desajeitado.

15 É preciso todo o caminho da experiência para se chegar a uma tradução consciente de si mesma. Toda primeira tradução é desajeitada: repete-se, aqui, no nível histórico o que advém a todo tradutor: uma tradução nunca é uma "primeira versão".

16 Se a défaillance, quer dizer, simultaneamente a incapacidade de traduzir e a resistência ao traduzir, afeta todos os atos de tradução, há, contudo, uma temporalidade desse ato (temporalidade tanto psicológica como cultural e linguística) que mostra que é no início (na primeira tradução) que défaillance está no seu auge.

17 O próprio autor sugere a relação entre os dois termos: défaillante e entropique.
} 
suprimi-la totalmente. Ao permitir o acolhimento da tradução no espaço da retradução (movimento crítico), surgiria uma multiplicidade de traduções, cada qual realizada a sua maneira, dentro do projeto de cada tradutor, promovendo assim uma diminuição dessa "entropia". E, com isso, num momento oportuno, o kairós - que podemos ler também como o momento em que as normas de tradução de uma determinada cultura se abrem a um novo modelo -, surge uma grande tradução, e, por algum tempo, para essa obra, não haverá mais a necessidade de retradução, ou, ao menos haverá uma diminuição dessa necessidade (ibid.). Vale salientar que Berman não fala em completude essencialista, definitiva, como um processo de hierarquização ao qual se referia Gambier. Esse processo, para Berman, deve ser sempre aberto, basta percebermos que para ele as grandes traduções são raras, porém não são estanques, e por isso mesmo em algum momento poderão solicitar por nova retradução.

Se estendermos nossa leitura do discurso de Berman, poderemos entender que ele fala, aqui, da necessidade de que a tradução literal, nos seus termos, ganhe lugar no espaço tradutório francês, o qual ele considerava exageradamente etnocêntrico. Sabemos que, para ele, era urgente e necessária uma abertura política para que isso acontecesse. Portanto, não é possível deixarmos fora desse viés político a sua discussão sobre a questão da retradução. A própria retradução do seu discurso se encaminha para isso.

No que diz respeito a "l'activité 'politique' (au sens large) en faveur de la traduction" (Berman, 2001, p. 16) ${ }^{18}$, como ele define uma das três relações com o traduzir que constituem a sua reflexão no texto "Au début était le traducteur" (2001) ${ }^{19}$, concluímos que o discurso político Bermaniano é um discurso de inclusão, e não de exclusão do que está posto. $\mathrm{O}$ autor, na verdade, pede equilíbrio. Na grande tradução, diz ele, a défaillance

reste présente, mais contrebalancée par un phénomène que nous pouvons appeler avec les traducteurs du XVIe siècle, la copia, la abondance. Dans la retraduction accomplie règne une abondance spécifique: richesse de la

\footnotetext{
18 a atividade "política" (no sentido largo) em favor da tradução.

19 "No início era o tradutor". (todas as traduções desse texto são de minha responsabilidade, para fins deste ensaio)
} 
langue, extensive ou intensive, richesse du rapport à la langue de l'original, richesse textuelle, richesse signifiante, etc. (Berman, 1990, p. 05, grifo do autor $)^{20}$.

Essa abundância diz respeito justamente a um movimento de clarificação e adaptação: acréscimos, cortes, embelezamentos, neologismos (mesmo quando não eles não estão lá no original). E isso deve acontecer ao mesmo tempo em que o tradutor também procura traduzir a letra. Ou seja, Berman tenta mostrar que a grande tradução irá impor um discurso diferente daquele discurso tradicional da perda, que é o discurso da abundância (ibid., p. 06).

Como manter o equilíbrio e não se deixar levar pelos perigos das deformações exageradas com as quais flerta o princípio da abundância?. Em "L'accentuation et le principe d'abondance en traduction" (1991) ${ }^{21}$ Berman dirá: pela autolimitação (p. 16). Basta lembrarmos que no sistema dialógico, presente na reflexão metacrítica, existe a possibilidade de autolimitação na obra. Como pressupunha o ato de elevação dos interlocutores acima do tema escolhido, ou, no caso, da tradução trabalhada, de maneira a possibilitar a observação da questão por diversos ângulos. Essa atitude leva em consideração que o agente do texto é capaz de, do mesmo modo, elevarse acima do seu próprio trabalho, atuando, assim, como elemento interno organizador e controlador das suas próprias escolhas.

Nesse sentido, toda grande tradução é o resultado do equilíbrio entre princípios opostos. Assim, tendo o princípio da abundância em equilíbrio com o princípio da tradução literal, o resultado é um texto enriquecido, plenamente realizado (ibid.). Através da tradução abundante, Berman instala um discurso positivo que pode embasar uma nova crítica da tradução, ou das traduções, em oposição ao discurso negativo da perda.

\footnotetext{
${ }^{20}$ permanece presente, mas contrabalanceado por um fenômeno que nós podemos chamar, com os tradutores do século XVI, a copia, a abundância. Na retradução realizada reina uma abundância específica: riqueza da língua, extensiva ou intensiva, riqueza do contato com a língua do original, riqueza textual, riqueza significante, etc.

21 "A acentuação e o princípio da abundância em tradução". (todas as traduções desse texto são de minha responsabilidade, para fins deste ensaio).
} 
C'est pourquoi la "critique d'une traduction" doit d'abord établir, avant tout examen ponctuel, si oui ou non une traduction obéit globalement à des principes. Elle doit, ensuite, déterminer la nature et le jeu mutuel de ces principes. Sans cette double détermination, elle n'a aucun sol de validité : elle n'est plus qu'un jeu de comparaison naïf entre un originel et sa traduction, qui débouche nécessairement : - sur la constatation que le traducteur a agi selon les "normes" de sa culture ; - sur la repérage accablant des "pertes" qui se sont produites pendant le transfert (ibid.) ${ }^{22}$.

Segundo Berman, esse enriquecimento promovido pelo ato de retraduzir, tão caro ao romantismo alemão, atualiza não só a cultura que traduz, mas também a cultura traduzida. Para a cultura que traduz isso significa: vida da língua, e para a traduzida: a sua sobrevida (ibid.).

Mas, como vimos, para que esse enriquecimento aconteça é preciso que surja o momento favorável, o kairós, que, de acordo com Berman, "est celui où se trouve brusquement et imprévisiblement (mais no sans raison) 'suspendue' la résistance qui engendre la défaillace, l'incapacité de 'bien' traduire une œuvre" (Berman, 1990, p. 6) ${ }^{23}$. O kairós, portanto, não pode ser reduzido apenas aos padrões socioculturais que facilitam tradução de uma obra. Pois, nesse sentido, esses padrões impõem uma permissão, ou não, para a tradução de determinada obra. E eles permitem no máximo, para retomar a distinção de Meschonnic, a introdução de uma obra. Não a sua tradução no sentido radical do termo, que implica necessariamente em retradução, em retraduções.

\section{Referências}

BERMAN, A. L'épreuve de l'étranger - Culture et traduction dans l'Allemagne romantique. Paris : Gallimard, 1984.

\footnotetext{
22 É por isso que a "crítica de uma tradução" deve primeiramente estabelecer, antes de todo o exame pontual, se uma tradução obedece ou não a esses princípios globalmente. Em seguida, ele deve determinar a natureza e o jogo mútuo desses princípios. Sem essa dupla determinação, ela não tem nenhum crédito: ela não é mais que um jogo de comparação ingênuo entre um original e sua tradução, que conduz necessariamente: - a constatação de que o tradutor agiu segundo as "normas" da sua cultura; ao rastreamento condenatório das "perdas" que foram produzidas durante a transferência.

${ }^{23}$ é aquele em que se encontra brusca e imprevisivelmente (mas não sem razões) "suspensa" a resistência que gera a défaillance, a incapacidade de "bem" traduzir uma obra.
} 
La traduction et la lettre ou l'auberge du lointain. Paris: Éditions du Seuil, 1985/1999.

La retraduction comme espace de la traduction. In: RetraduireRevue Palimpsestes, $\mathrm{n} \times 4$, octobre. Paris: Publications de la Sorbonne Nouvelle, 1990 p. 01-07.

. L'accentuation et le principe d'abondance en traduction. In: $L a$ mise en relief - Revue Palimpsestes, no5, janvier. Paris: Éditions de l’Espace Européen, 1991, p. 11-17.

Au début était le traducteur. In: TTR - traduction, terminologie, rédaction, vol. 14, n², 2001, p. 15-18. http://id.erudit.org/iderudit/000566ar Jacques Amyot, traducteur français - Essai sur les origines de la traduction en France. Paris: Belin, 2012.

GAMBIER, Y. La retraduction : ambiguïtés e défis. In: Autour de la retraduction - perspectives littéraire européennes. Direction de Enrico Monti et Peter Schnyder. Paris: Orizons, 2011, p. 49-66.

GARMA-BERMAN, I. Note éditoriale. In: Berman, A. L'Âge de la traduction"La tâche du traducteur" de Walter Benjamin, un commentaire. Paris : Presses Universitaires de Vincennes, 2008, p. 05-07.

MEDEIROS, C. L. De. A forma do paradoxo: Friedrich Schlegel e a ironia romântica. In: Trans/Form/Ação, vol. 37, n²1, Marília - SP, 2014, p. 51-60.

SELIGMANN-SILVA, M. A redescoberta do Idealismo mágico. In: Benjamin, W. O conceito de crítica de arte no Romantismo alemão. Tradução de Márcio Seligmann-Silva. São Paulo: Iluminuras, 2011, p. 09-14.

SUZUKI, M. O gênio romântico - Crítica e história da filosofia em Friedrich Schlegel. São Paulo: Iluminuras, 1998.

Resumo: Este ensaio apresenta o desenvolvimento do conceito de retradução no pensamento de Antoine Berman.

Résumé: Cet essai présent le développement du concept de retraduction dans la pensée d' Antoine Berman. 